\title{
Effect of Palm Oil Bunches Microfiller on LDPE-recycled Composite Tensile Strength through Melt Blending Process
}

\section{Zulnazri and Sulhatun}

\author{
Chemical Engineering Department, University of Malikussaleh, Lhokseumawe, \\ Aceh, Indonesia
}

\begin{abstract}
Purpose - This purpose of the research is to investigate the process of manufacturing LDPE recycle thermoplastic composites with reinforcement oil palm empty fruit bunch (OPEFB) biomass microfillers.

Design/Methodology/Approach - Methods of physical and chemical modification of OPEFB fibers into the LDPE matrix and the addition of some compatibilizer such as MAPE and xylene process through melt blending can improve mechanical properties, electrical properties, biodegradability, and improve the morphology of composites.

Research Limitations/Implications - These composites are prepared by the following matrix ratio: filler (70:30) $\%$ and filler size $(63,75,90$, and 106) $\mu \mathrm{m}$. The LDPE plastic is crushed to a size of $0.5-1 \mathrm{~cm}$, then pressed with hot press free heating for $5 \mathrm{~min}$ and with a pressure of $10 \mathrm{~min}$ at $145{ }^{\circ} \mathrm{C}$. Based on the characterization obtained, the tensile strength and the high impact on the use of $106 \mu \mathrm{m}$ filler is $13.86 \mathrm{MPa}$ and $3,542.6 \mathrm{~J} / \mathrm{m}^{2}$, and thermal stability indicates the degradation temperature $\left(\mathrm{T}_{0}\right) 497.83{ }^{\circ} \mathrm{C}$. FT-IR analysis shows the presence of functional groups of cellulose and lignin molecules derived from TKKS collected in the composite.

Practical implications - Based on the characterization obtained, this composite can be applied as furniture material and vehicle dashboard.

Originality/value - Composites obtained from recycle of LDPPE plastics waste has some advantages such as good compatibility and high tensile strength. This composite used the OPEFB filler whose size is in micrometer, and so this product is different from other products.
\end{abstract}

Keywords LDPE, microfiller, OPEFB, composite

All papers within this proceedings volume have been peer reviewed by the scientific committee of the Malikussaleh International Conference on Multidisciplinary Studies (MICoMS 2017).

\section{Introduction}

Thermoplastic polymers are widely used in many sectors of life, and almost every product uses plastic as packaging or as a base material. Every year about 100 million tons of plastic is produced worldwide for use in various industrial sectors. Low-density polyethylene

(C) Zulnazri and Sulhatun. Published in the Emerald Reach Proceedings Series. Published by Emerald Publishing Limited. This article is published under the Creative Commons Attribution (CC BY 4.0) licence. Anyone may reproduce, distribute, translate and create derivative works of this article (for both commercial and non-commercial purposes), subject to full attribution to the original publication and authors. The full terms of this licence may be seen at http://creativecommons.org/licences/by/4.0/ legalcode

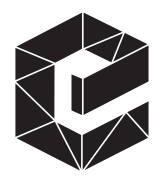

Emerald Reach Proceedings Series pp. $503-509$ 
Proceedings of MICoMS 2017

\section{4}

(LDPE) is one of the most widely produced thermoplastics. This plastic is a synthetic polymer that cannot be degraded by micro-organisms in the environment, thus potentially threatening the survival of the earth. Efforts to reduce environmental pollution can be done by recycling the plastic into a new product. One method used depolymerization, for example, polyethylene terephthalate type used terephthalate acid, and ethylene glycol to make fiber composites, molding materials, and plastic bottles (Martaningtyas, 2004).

A common method of making composites is plastic mixed with fillers, and then melt blending with hot press or extruder to produce composites (Zulnazri, 2014). Oil palm empty fruit bunch (OPEFB) as a filler has many advantages, including low density, large deformability, flexible, non-heat-generating properties during the process and derived from renewable resources. Thermoplastic and filler material of plant fibers is in principle an incompatible material, due to polarity differences, requiring modification of processes such as in situ cross-linking, addition of the accelerator (compatibilizer), and the copolymerization of functional groups in the polymer and filler (Basuki, 2004). Some chemicals developed for the compatibility between the two materials are maleic anhydrate (MAH) modified-polypropylene, poly [methylene (polyphenl isocyanate)], poly (propylene-acrylic acid), and xylene (Rozman, 2002). The lignocellulosic-based filler developed now is OPEFB. OPEFB is very potential to be used as a filler due to its abundant presence in nature, besides OPEFB can add composite strength due to high cellulose fiber content, which is $52 \%$ (Zulnazr, 2017).

Previous studies have reported that OPEFB fibers can be used as fillers to produce polypropylene composites. Maximum tensile strength of the composite is obtained when the filler content is $20 \%$ by weight, although elongation shows a decreasing trend with increased filler. The addition of acrylic acid gives compatibility between filler and polypropylene (Basuki, 2004).

The reaction of MAH with OPEFB has been observed with FT-IR analysis showing the peak properties of MAH in the OPEFB filler. Composites with MAH-treated fillers exhibit high flexural and impact properties. Scanning electron microscopy (SEM) exhibits good adhesion and compatibility properties between OPEFB and thermoplastic matrices as a result of chemical modification using MAH (Rozman, 2001). Mechanical properties such as tensile and flexural of composites-cellulose filler can be increased by using coupling and bonding agent of maleic anhydride-grafted polypropylene and multifunctional acrylates; this material can increase the bond between cellulose and polymer matrix (Khalid, 2007).

Modification of the composite-making process using reactive techniques has been reported by several researchers. In this research, microfiller composite is made from LDPE recycle polymer and OPEFB fiber with micrometer size, and mixed with the initiator in the form of maleic anhydride polyethylene (MAPE) and xylene as the compatibility agent, then processed further using melt blending method, the product obtained is used for the furniture material.

\section{Materials and methods}

\subsection{Preparation of raw material and composite manufacture}

OPEFB fibers are milled with grinding mill and sieved with mesh sizes up to 63, 75, 90, and $106 \mu \mathrm{m}$. The LDPE plastic is crushed to a size of $0.5-1 \mathrm{~cm}$.

Installed three-neck flask with condenser: Solution (MAPE 8\% in xylene) of $10 \mathrm{ml}$ mixed in OPEFB filler until evenly distributed. Then the matrix and the filler were mixed with the ratio $\left(80: 20,70: 30\right.$, and 60:40), the mixture was put in a three-neck flask and heated at 40-50 ${ }^{\circ}$ $\mathrm{C}$, stirred to homogeneous for $\pm 15 \mathrm{~min}$. The mixture is removed from the three-neck flask, 
poured into aluminum foil, and left to room temperature. The mixture is molded to ASTM D256 standard with hot press for $20 \mathrm{~min}$ at $145^{\circ} \mathrm{C}$ and $10 \mathrm{~kg} / \mathrm{cm}^{2}$ pressure. After reaching room temperature, the composite is expressed and tested.

\subsection{Characterization}

(1) Tensile strength: Specimens prepared in accordance with ASTM mounted on a tensile test equipment. After testing, obtained the value of the maximum pressure and crosssectional area, then can be calculated the value of tensile strength with the following equation (ASTM D638-99):

$$
\sigma=\frac{P}{A}
$$

where $\sigma$ is the tensile strength $\left(\mathrm{kgf} / \mathrm{cm}^{2}\right), A$ is the area cross-section $\left(\mathrm{cm}^{2}\right)$, and $P$ is the maximum pressure (kgf), while the value of elongation is calculated by the following equation:

$$
\sum=\frac{\Delta L}{L} \times 100 \%
$$

where $\Sigma$ is the estrangement (\%), $\Delta L$ is the difference in length after the tensile test (cm), and $L$ is the length of the initial test sample (cm).

(2) Surface morphology by SEM

(3) Thermal analysis by differential scanning calorimetry (DSC).

(4) Analysis of chemical structure by infrared (FT-IR).

\section{Result and discussion}

\subsection{Tensile strength}

The tensile strength and elongation data of the composite are shown in Table 1, with a ratio of 70:30, with filler sizes: $63,75,90$, and $106 \mu \mathrm{m}$.

Figure 1 shows the given load/force value for the time of each composite with the ratio (70:30) with the filler size: (1) $63 \mu \mathrm{m}$, (2) $75 \mu \mathrm{m}$, (3) $90 \mu \mathrm{m}$, and (4) $106 \mu \mathrm{m}$. The tensile strength and elongation data of the composite are shown in Table 2 . The $30 \%$ filler content can increase tensile strength when mixtures are processed in the presence of MAP as initiators. However, if the increased amount of filler can cause a decrease in tensile strength, this is due to a decrease in the compatibility of both materials and the role of the MAP initiator is reduced. Therefore, the maximum composition of the composite mixture contains $30 \%$ filler and $70 \%$ matrix, which is triggered with an $8 \%$ MAP dispersant and moistened with $0.5 \%$ xylene. Dispersant may increase the dipole property, wherein the carboxylate group allows binding to

\begin{tabular}{lccccc}
\hline No. & $\begin{array}{c}\text { Filler Size } \\
(\mu \mathrm{m})\end{array}$ & $\begin{array}{c}\text { Tensile Strength } \\
(\mathrm{MPa})\end{array}$ & $\begin{array}{c}\text { Elongation at Break } \\
(\%)\end{array}$ & $\begin{array}{c}\text { Yield Strength } \\
(\mathrm{Mpa})\end{array}$ & $\begin{array}{c}\text { Elastic Modulus } \\
(\mathrm{MPa})\end{array}$ \\
\hline 1. & 63 & 12.495 & 5.216 & 10.507 & 5.019 \\
2. & 75 & 6.218 & 4.932 & 3.453 & 3.299 \\
3. & 90 & 7.716 & 3.943 & 5.315 & 2.980 \\
4. & 106 & 13.867 & 9.144 & 9.752 & 2.470 \\
\hline
\end{tabular}
(1)

Effect of Palm Oil Bunches Microfiller

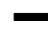


Proceedings of MICoMS 2017

\section{6}

Figure 1.

Composite Tensile Test Graph (70:30) with the Filler Size: (1) $63 \mu \mathrm{m},(2) 75 \mu \mathrm{m}$, (3) $90 \mu \mathrm{m}$, and (4) 106 $\mu \mathrm{m}$

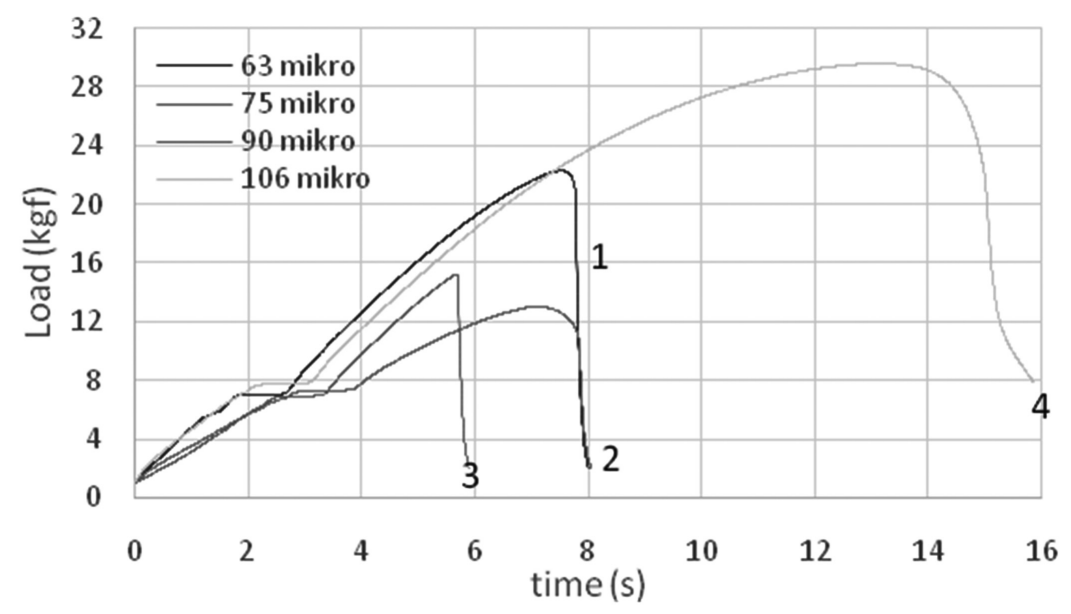

the lignocellulose filler surface and acts as an internal plasticizer in the composite (Basuki et al., 2004). From the graph, the high tensile strength is seen in the composite with $106 \mu \mathrm{m}$ filler size, while the lower filler size has lower tensile strength, this is because the smaller the filler size, the smaller the compatibility level of the matrix with OPEFB.

\subsection{Surface Morphology}

The surface morphology of LDPE composites with OPEFB fillers is investigated by SEM. Reactive mechanism of LDPE surface system with OPEFB filler is triggered by MAP and xylene. The surface structure of the LDPE composite containing 30\% lignocellulose-OPEFB and $8 \%$ MAP is shown in Figure 2. SEM shows that the MAP compatibilizer accumulates on the lignocellulose surface and binds with LDPE. The presence of MAP and xylene can increase the compatibility of the composites by increasing the adhesion force of the interface on the matrix and filler, it is clear that there are pores of the surface and forming the bonding marks and gluing firmly when the composite is pulled off. Several parts show the LDPE breaking up by leaving the OPEFB fiber section. The overall fracture and the breakup in composites with $63 \mu \mathrm{m}, 75 \mu \mathrm{m}, 90 \mu \mathrm{m}$, and $106 \mu \mathrm{m}$ filler sizes are the same.

\subsection{Thermal Properties}

The melting temperature and decomposition temperature of the composites are investigated with differential scanning calorimetry (DSC). Figure 3 shows the DSC thermogram of the composite ratio (70:30) \% and 8\% MAP with filler size: (a) $63 \mu \mathrm{m}$, (b) $75 \mu \mathrm{m}$, (c) $90 \mu \mathrm{m}$, and (d) $106 \mu \mathrm{m}$. Table 2 shows melting and decomposition temperature. Composite decomposition made of thermoplastic is shown by the presence of melting temperature. Melting temperature

Table 2.

Decomposition Temperature LDPE Composites with Different Size Fillers

\begin{tabular}{lcccc} 
No. & Particle Size $(\mu \mathrm{m})$ & Melting Temp. $\left({ }^{\circ} \mathrm{C}\right)$ & Start Temp. $\left({ }^{\circ} \mathrm{C}\right)$ & Decomposition Temp. $\left({ }^{\circ} \mathrm{C}\right)$ \\
\hline 1. & 63 & 140 & 129.61 & 497.28 \\
2. & 75 & 140 & 26.73 & 335.27 \\
3. & 90 & 140 & 33.41 & 399.75 \\
4. & 106 & 140 & 25.27 & 497.83
\end{tabular}



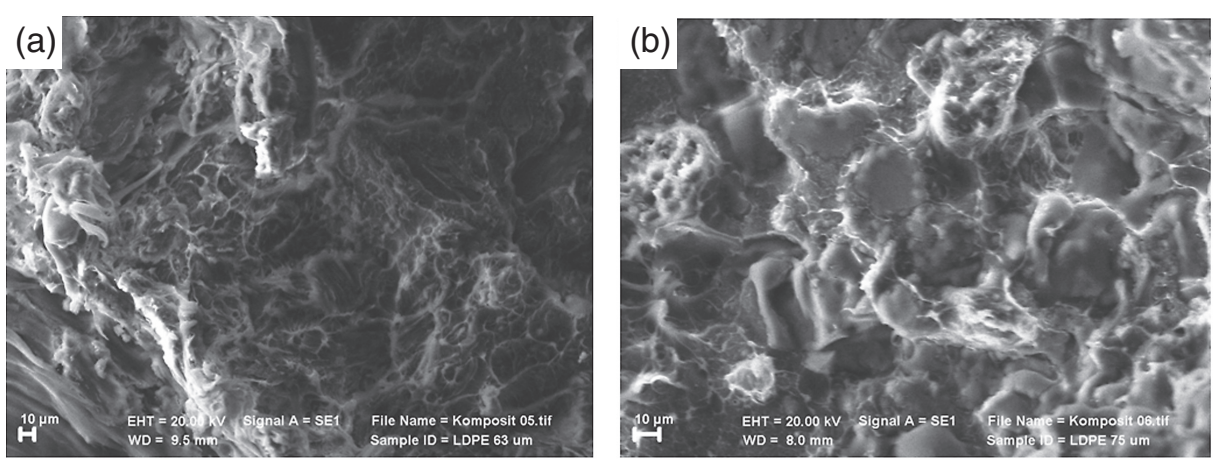

Effect of Palm

Oil Bunches Microfiller
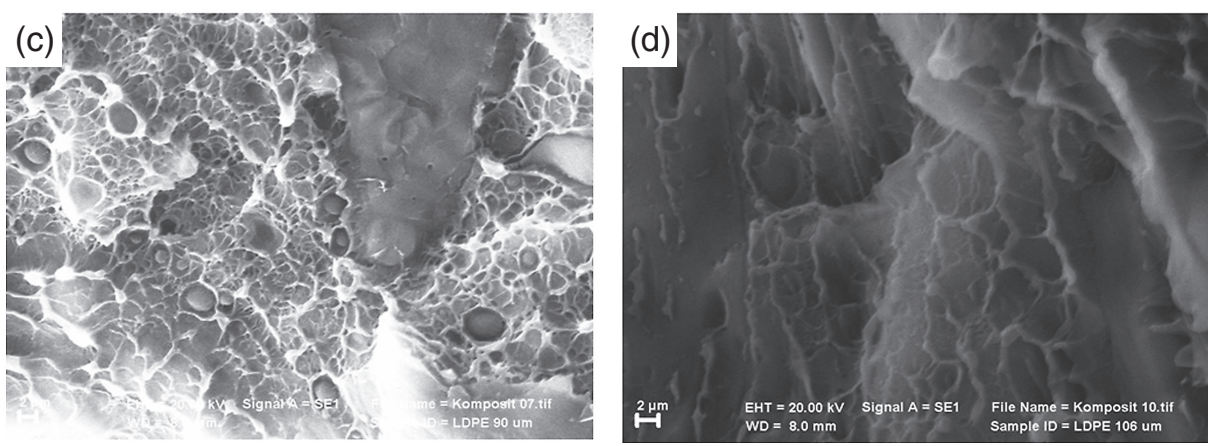

507

describes the phase change from solid to liquid without changing composition. This temperature is the critical temperature at which the polymer loses its overall crystallinity. After passing the melting temperature, the composite will decompose, there will be changes in the composition and chemical properties of the composite. The images show the very high composite degradation temperature which indicates that the composite obtained is resistant to heat. The composite material has decreased the melting point along with the addition of filler, this is because the polymer chains are physically degraded, meaning the polymer chains are pressed by the filler to break the polymer molecule chain bond.

\subsection{Chemical Structure Analysis}

The functional group analysis of OPEFB and MAP was investigated by infrared spectrum. Figure 4 shows the FT-IR spectrum. Table 3 displays the placement of the functional group vibrational region. Spectrum shows the widespread absorption peak in the 3,200-3,500 $\mathrm{cm}^{-1}$ and the wavelength region is the widening area of $\mathrm{O}-\mathrm{H}$ indicating characteristic of phenolic and alcohol believed to be lignin, hemicellulose and cellulose as the main constituent compound of OPEFB. The peak in the region of $3,000-2,800 \mathrm{~cm}^{-1}$ is the $\mathrm{C}-\mathrm{H}$ region which is the alkene functional group derived from the LDPE polymer. The peaks in the region of $1,750-1,600 \mathrm{~cm}^{-1}$ are strongly suspected $\mathrm{C}=\mathrm{O}$ regions which are ester functional groups of lignin structures which are compounds of OPEFB biomass composers. The area of $1,300-1,250 \mathrm{~cm}^{-1}$ is a stretch of $\mathrm{C}-\mathrm{O}$ which is characteristic of glucosidic functional groups derived from cellulose and hemicellulose. The spectrum 
Proceedings of

MICoMS 2017

\section{8}

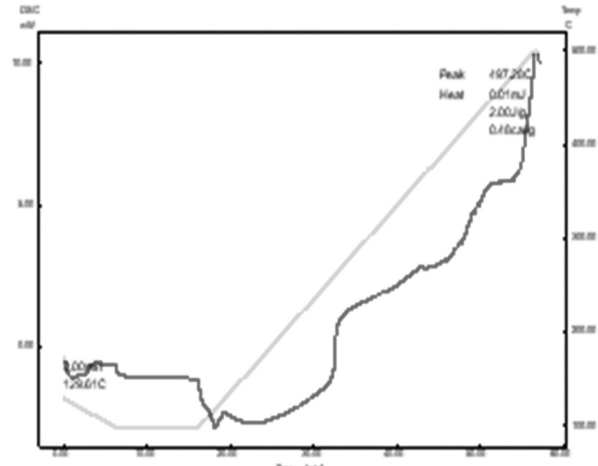

(a)

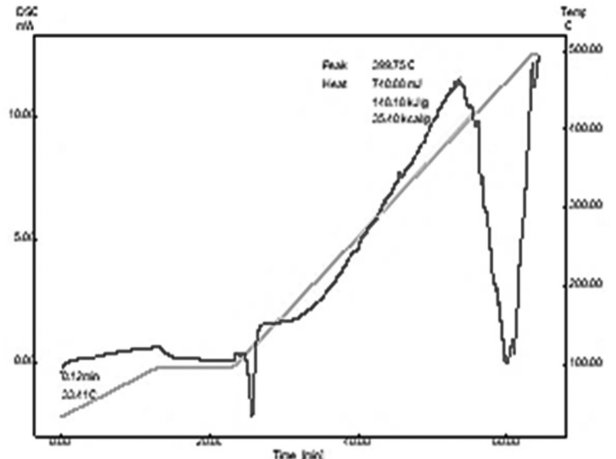

(c)

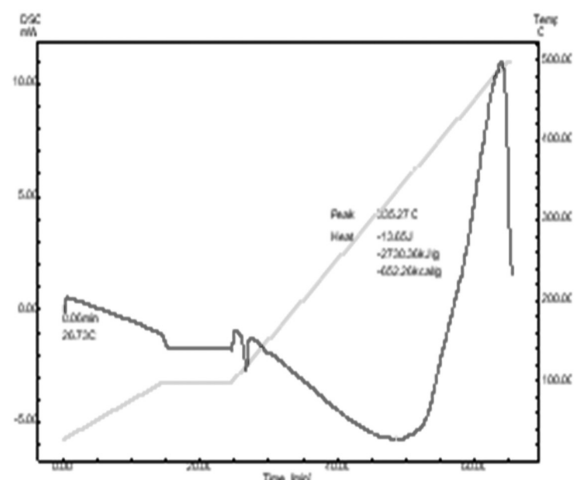

(b)

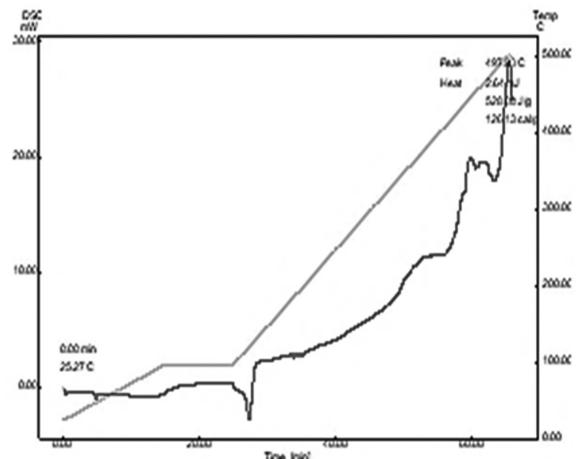

(d) (d) $106 \mu \mathrm{m}$

Figure 3.

The DSC

Thermogram of the Composite Ratio (70:30) with the Filler Size (a) $63 \mu \mathrm{m}$, (b) 75 $\mu \mathrm{m}$, (c) $90 \mu \mathrm{m}$, and
Table 3.

FT-IR Spectrum of Functional Groups LDPE Microcomposites shows that all of the highly compatible molecular lignocelluloses react with the polyethylene matrix during processing with the help of the xylene initiator. This is consistent with that expressed by Basuki et al. (2004), where the acrylic compatibilizer is able to bind at high levels in the polypropylene matrix during the reactive process in the presence of peroxides.

\section{Conclusion}

LDPE plastic blending process with OPEFB filler can be done at a composite ratio of (70:30) \% using $8 \%$ MAP with good mechanical properties. The composite has good tensile strength and

\begin{tabular}{lccc}
\hline Functional Groups & Wave Number $\left(\mathrm{cm}^{-1}\right)$ & OPEFB & LDPE \\
\hline $\mathrm{O}-\mathrm{H}$ & $3,500-3,200$ & $\vee$ & - \\
$\mathrm{C}-\mathrm{H}$ & $3,000-2,800$ & $\vee$ & $\vee$ \\
$\mathrm{C}=\mathrm{O}$ & $1,750-1,600$ & $\vee$ & - \\
$\mathrm{C}=\mathrm{C}$ & $1,500-1,450$ & $\vee$ & $\vee$ \\
$\mathrm{C}-\mathrm{O}$ & $1,300-1,250$ & $\vee$ & $\vee$ \\
$-\mathrm{CH}_{3},-\mathrm{CH}_{2}$, & $1,250-1,000$ & $\vee$ & $\vee$ \\
\hline
\end{tabular}




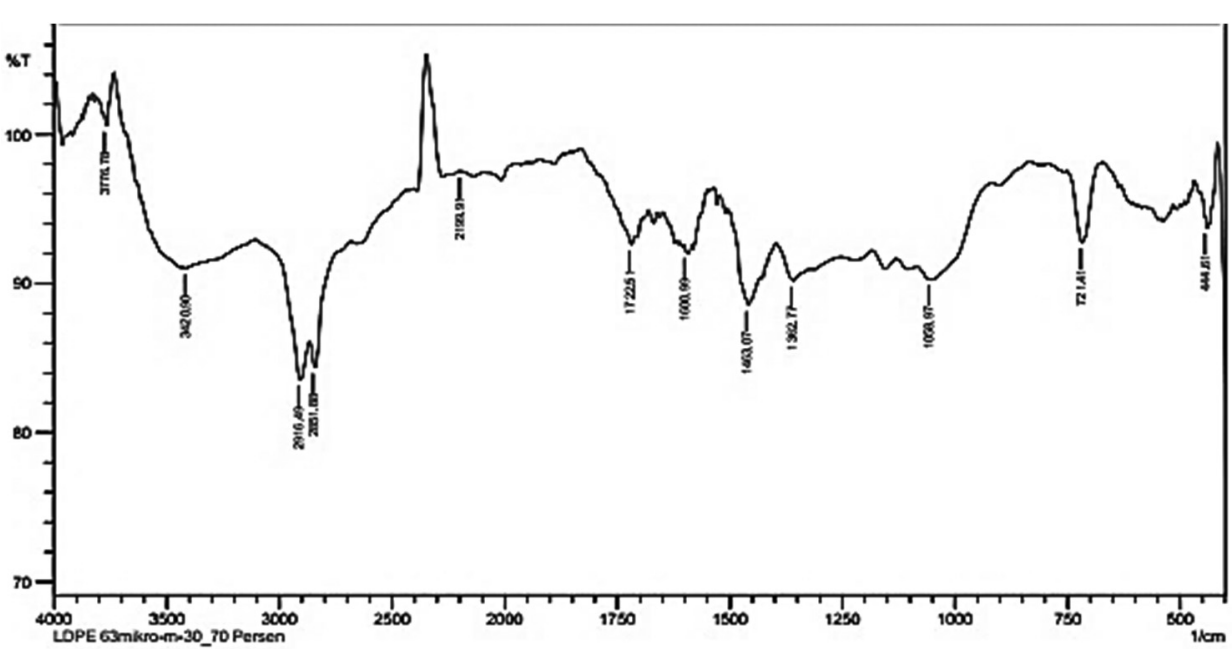

Effect of Palm

Oil Bunches

Microfiller

Figure 4.

FT-IR Spectrum of

Composite Ratio

(70:30) with 63- $\mu \mathrm{m}$

Filler Size

impact obtained by using a $63-\mu \mathrm{m}$ filler, which is $12,495 \mathrm{MPa}$ and $3,776 \mathrm{~J} / \mathrm{m}^{2}$. The smaller the fiber size, the higher the composite quality, where fiber particles can bind compatibly with LDPE matrices. The composite obtained has high durability and good semiconductor properties.

\section{References}

ASTM (D638-99), American Society for Testing and Materials Information Handling Services. Standard Test Method for Tensile Properties of Plastics, pp. 1-13, United States of America, (1 December 2006).

Basuki, W. (2004). “Oil Palm Empty Fruit Bunch Filled Popypropylene Composites”, International Journal of Polymeric Materials, Vol. 53, pp. 295-306.

Khalid, M. (2007). "Comparative Study of Polypropylene Composites Reinforced with Oil Palm Empty Fruit Bunch Fiber and Oil Palm Derived Cellulose”. Journal of Material Design, Vol. 29, pp. 173-178.

Martaningtyas. (2004). Potential Plastic "Biodegradable”. Institut Pertanian Bogor, Bogor.

Rozman, H.D. (2001). "Polypropylene-Oil Palm Empty Fruit Bunch-Glass Fibre Hybrid Composites: A Preliminary Study on the Flexural and Tensile Properties". European Polymer Journal, Vol. 37, pp. 1283-1291.

Rozman, H.D. (2002). "Flexural and Impact Properties of Oil Palm Empty Fruit Bunch (OPEFB)Polypropylene Composites - The Effect of Maleic Anhydride Chemical Modification of OPEFB". Journal of Polymer Testing, Vol. 22, pp. 335-341.

Zulnazri. (2014). "High Density Polyetylene-Oil Palm Empty Fruit Bunch Filled Micro Composites Using Melt Blending Process". In Proceedings AIC Unsyiah, 22-24 October 2014, Banda Aceh.

Zulnazri, (2017). Hydrolyzed of Cellulose from Oil Palm Empty Fruit Bunch to Produced Cellulose Nanocrystals by Sonication - Hydrothermal Method. Dissertation, ITS, Surabaya.

\section{Corresponding author}

Zulnazri can be contacted at zulnazri@unimal.ac.id 